\title{
Distributed selves: personal identity and extended memory systems
}

\author{
Richard Heersmink ${ }^{1}$
}

Received: 12 February 2016 / Accepted: 15 April 2016 / Published online: 28 April 2016

(C) Springer Science+Business Media Dordrecht 2016

\begin{abstract}
This paper explores the implications of extended and distributed cognition theory for our notions of personal identity. On an extended and distributed approach to cognition, external information is under certain conditions constitutive of memory. On a narrative approach to personal identity, autobiographical memory is constitutive of our diachronic self. In this paper, I bring these two approaches together and argue that external information can be constitutive of one's autobiographical memory and thus also of one's diachronic self. To develop this claim, I draw on recent empirical work in human-computer interaction, looking at lifelogging technologies in both healthcare and everyday contexts. I argue that personal identity can neither be reduced to psychological structures instantiated by the brain nor by biological structures instantiated by the organism, but should be seen as an environmentally-distributed and relational construct. In other words, the complex web of cognitive relations we develop and maintain with other people and technological artifacts partly determines our self. This view has conceptual, methodological, and normative implications: we should broaden our concepts of the self as to include social and artifactual structures, focus on external memory systems in the (empirical) study of personal identity, and not interfere with people's distributed minds and selves.
\end{abstract}

Keywords Personal identity · Narrative self $\cdot$ Extended mind $\cdot$ Distributed cognition · Transactive memory $\cdot$ Lifelogging

Richard Heersmink

richard.heersmink@gmail.com

1 Macquarie University, Sydney, Australia 


\section{Introduction}

As an adaptive strategy, the human cognitive system has evolved to offload and incorporate information in the environment to complement the limitations in its capability to store and process information (Donald 1991). Thus rather than seeing our cognitive system as instantiated only by the brain, we should see it as spread out across embodied brains and information-structures in the environment (Hutchins 1995; Clark 1997; Rowlands 1999; Menary 2007; Sutton 2010). Memory systems, in particular, are typically instantiated in distributed networks, as the environment affords easy and often reliable storage of information (Michaelian and Sutton 2013). On such an extended and distributed cognition view, our cognitive capacities depend on and are (sometimes) constituted by a complex web of social and artifactual structures. Synchronically, human cognizers thus form coupled systems with certain aspects of the environment in which they are situated (Clark and Chalmers 1998).

Neo-Lockean views on personal identity emphasize memory as an important criterion of persistence of personhood over time. Marya Schechtman (1994, 1996), for example, argues that we summarize and condense our past experiences into an autobiographical narrative, which is constitutive of our diachronic self. So who we are as persons is defined and constituted by our autobiographical narrative. Given this emphasis on memory, there is an obvious connection between extended and distributed approaches to cognition and neo-Lockean approaches to personal identity ${ }^{1}$ (Wilson and Lenart 2014). In this paper, I further conceptualize this connection by developing the following argument: if memory is often distributed and if the self is partly constituted by our memory, then the self is also distributed. To develop this argument, I draw on recent empirical work in human-computer interaction, looking at lifelogging technologies in both healthcare and everyday contexts (Berry et al. 2007; Doherty 2012; Crete-Nishihata 2012). These are memory technologies that record personal experiences. A key example is SenseCam, a small wide-angle camera worn around one's neck, taking a picture with a certain interval or when its sensor detects some environmental change. These pictures are then edited into a visual lifelog with a certain narrative structure, transforming, aiding, and in some cases constituting one's autobiographical narrative.

The analysis unfolds as follows. First, I outline situated cognition theory with a focus on extended and distributed memory systems. Second, I present the current debate on whether the self is constituted by an embodied organism or partly constituted by external informational structures. Third, I develop a view on the self as essentially distributed across embodied agents and external information located either in other agents (social) or in objects (artifactual). Fourth, I reflect on some of the normative aspects of lifelogging and our distributed selves.

\section{Situated and distributed memory}

In the last thirty years or so, new views on human cognition emerged, arguing that our cognitive systems are often scaffolded and sometimes constituted by external resources

1 The terms "self", "personhood", and "personal identity" are used interchangeably throughout this essay. 
such as other people and artifacts. Situated cognition theory is typically used as an umbrella term to cover these views, including embodied, embedded, extended, distributed and collective cognition. ${ }^{2}$ It is a set of loosely related approaches that underline the importance of our embodied interactions with the socio-technological environment for understanding our cognitive capacities, providing an alternative for neuro-centric and individualist views on cognition. Situated views point out that our embodied brains are powerful pattern recognition and completion systems, but have limited information-storage and processing capacities. There are, for instance, limitations in information-processing speed, accuracy, and capacity. To overcome these limitations, we rely on and incorporate the complementary properties and functions of external artifacts and other people (Sutton 2010). As Daniel Dennett writes: "The widespread practice of offloading releases us from the limitations of our animal brains" (1996, p. 135). Below I briefly outline how we offload, rely on and incorporate information in other people and artifacts, focussing on memory.

\subsection{Transactive memory}

Daniel Wegner and colleagues (Wegner et al. 1985; Wegner 1995; see also Theiner 2013) advanced an empirical view on social memory, arguing that dyads and other intimate social groups often develop transactive memory systems. In such distributed memory systems, there is a cognitive interdependence between group members, which means that agents rely on each other for their cognitive performance. Transactive processes are essentially communicative or interactive processes between group members, which most obviously occur at the encoding and retrieving stage of memory processing. During transactive encoding, group members discuss incoming information and negotiate who has to store the information and in which form. During transactive retrieval, group members have to determine where the information is stored, which can involve the integration of information stored in different brains. Consider the following example of transactive retrieval from Harris et al. (2010):

F: And we went to two shows, can you remember what they were called?

M: We did. One was a musical, or were they both? I don't ... no ... one ...

F: John Hanson was in it.

M: Desert Song.

F: Desert Song, that's it, I couldn't remember what it was called, but yes, I knew John Hanson was in it.

M: Yes

In this example of transactive remembering, a long-married couple give each other cues such that they jointly recall information that both individuals had forgotten. Wegner et al. (1985) emphasize the interdependency of individual memory systems and therefore point out that transactive memory systems cannot be reduced to individual memory. It is an emergent group-level property that exists only when people interact and communicate in the right sort of way (Theiner 2013). So, in order to empirically

2 Sometimes the phrase "4e cognition" is used, which is an acronym for embodied, embedded, extended, and enactive cognition. 
study and theoretically conceptualize such systems, we need to enlarge the unit of analysis from a single agent to various agents interacting with each other. If we would only focus on single agents in the Desert Sing example, we would not be able to fully explain the outcome of the system. This real-world example thus suggests that transactive memory systems are group-level properties and cannot be reduced to its individual members.

\subsection{Artifactual memory}

In addition to relying on and collaborating with other people to perform memory tasks, we also quote often use information stored in artifacts. An often mentioned example of artifactual memory in the extended cognition literature is Otto and his notebook. Otto is a man in the first stages of Alzheimer's disease, using a paper notebook to aid and supplement his biological memory systems (Clark and Chalmers 1998). He always carries it with him because he needs the information in the notebook to successfully get around in the world. Importantly, information in Otto's notebook plays relevantly similar functional roles as information stored in his biological memory systems in guiding Otto's actions. The information is further easily accessible, reliably there when needed, trustworthy, has been endorsed at some point in the past and indeed is there because of this endorsement. On an extended and distributed cognition view, "a cognitive process is delimited by the functional relationships among the elements that participate in it, rather than by the spatial colocation of the elements" (Hollan et al. 2000, p. 176). ${ }^{3}$ So the function and the way it is used and integrated into Otto's cognitive system are what matters, not that it is external to the organism.

Our memory is scaffolded by varies other external artifacts. For example, we put labels on objects so we do not have to remember where they are; we use diaries and calendars to remember our appointments; shopping lists to remember the items we need to buy; and books, libraries, databases, and the Internet to store and look up all kinds of information. These cognitive artifacts have been intentionally designed to serve memory supporting functions, but we also often offload memory functions onto the environment by improvising. Bartenders, for example, are typically under a lot of pressure and have to deal with certain cognitive and environmental constraints. In order to deal with the cognitive overload, they structure distinctively shaped drink glasses such that they correspond to the sequence of the ordered drinks. Consequently, the bartenders do not have to internally remember the order of the drinks, but offload it onto their environment (Beach 1988). Cooks, likewise, offload memory tasks by actively structuring their work-environment. The ingredients and equipment are arranged such that they facilitate the cooking process by offloading the order of the steps of the cooking process onto the environment. Kirsh (1995) refers to this as "the intelligent use of space" in which the arrangement of artifacts is itself a cognitive artifact. Material culture thus plays an important role in human memory (Donald 1991).

\footnotetext{
3 I am using the phrases "extended cognition" and "distributed cognition" more or less interchangeably in this paper, as both approaches claim that informational artifacts can be constitutive of a wider cognitive system, but there are differences between the two approaches. See Hutchins (2014) for an analysis of some of these differences in terms of examples, method, and explanatory scope.
} 


\subsection{Situated autobiographical memory}

As the Desert Song example shows, transactive memory often has a strong autobiographical or episodic component, because transactive memory partners typically have many shared past experiences. Most examples of artifactual memory in the situated cognition literature, however, concern information that scaffolds and is integrated with short-term or semantic memory systems but not so much with autobiographical memory. It is, however, important to point out that artifacts also quite often scaffold autobiographical memory. Some people, for example, have a journal in which they write their daily experiences, which is a medium used to express oneself and organise one's thoughts, but also used as an external autobiographical memory system. Other examples are photos and photo albums; travel blogs; significant objects like souvenirs, jewellery, or books; status updates on social media like Facebook and Twitter; and uploaded pictures on social media like Flickr, Facebook or Instagram. Interacting with these artifacts and the information they contain often evoke autobiographical and sometimes emotional responses (Hoven 2014).

Relatively new and very powerful autobiographical memory technologies are now emerging referred to as "lifelogging technologies" (O'Hara et al. 2008; Hoven et al. 2012). These are digital artifacts and applications that record aspects of one's everyday life. Such technologies include wearable cameras automatically taking pictures with a certain interval (e.g., SenseCams), applications recording screen behaviour, and wearable sensors recording biological variables (e.g., heart rate, temperature, blood oxygen level, and EEG) or environmental variables (e.g., location or temperature). Vannevar Bush's concept of the "memex" (a portmanteau of memory and index) was an early precursor of lifelogging. A memex is a "device in which an individual stores all his books, records, and communications, and which is mechanised so that it may be consulted with exceeding speed and flexibility. It is an enlarged intimate supplement to memory" (1945, p. 6). Bush suggested that scientists could wear glasses that can take pictures of what they see and that entries in the memex were annotated and easily searchable. Computer pioneer Gordon Bell developed one of the most ambitious (and controversial) examples of contemporary lifelogging called the "MyLifeBits" project. Inspired by Bush's vision of the memex, Bell digitized articles, books, music, phone calls, letters, photos, presentations, and home movies, and stored them in a lifelog (Bell and Gemmell 2009). Software allows him to search for dates and keywords in the lifelog, which, for Bell, functions as an elaborate external autobiographical memory system. A practical problem with some of these lifelogging technologies is that they capture too much information, leading to information overload. So the challenge is to construct lifelogs that are manageable and cognitively meaningful to the user (Doherty 2012). More on this below in Sects. 4 and 5.

There is a small subculture of people who actively and consistently use these technologies to record their everyday life sometimes called the "quantified self movement", making elaborate lifelogs about their daily life. Most people, however, are not interested in creating elaborate lifelogs, but do sometimes use lifelogging applications, for example when they make a (digital) photo album of their past holiday, track their route with their smartphone when they go jogging, or do not delete emails such that 
they have a database of previous email communication. Importantly, some of these technologies are used in healthcare to help patients with memory disorders. SenseCams, in particular, are useful and effective to record aspects of a patient's daily life (Hodges et al. 2011). It has been shown that reviewing a visual lifelog has beneficial effects on a patient's autobiographical memory such as maintaining the integrity, delay the disintegration, or in some cases replace autobiographical memory (Berry et al. 2007; Doherty 2012; Crete-Nishihata 2012). Elsewhere I argued that lifelogging technologies change our embodied self, as the information they provide about bodily and environmental states transforms the kind of relationship we have to our embodiment (Smart et al. 2016). In this paper, I elaborate on this claim and argue that it is not just our embodied self but also our narrative self that is transformed by lifelogging technologies.

\section{Extended cognitive systems and personal identity}

Having briefly outlined situated cognition theory and the distributedness of both semantic and episodic memory, I now continue by summarizing the current debate on the extended self. Some theorists argue that the notions of extended and distributed cognition imply an extended and distributed self (Clark and Chalmers 1998; Clark 2005; Anderson 2008), whereas others deny this (Baker 2009; Olsen 2011; Buller 2013). In his early work, Clark (1997) speculates about the possibility of an extended self and agency, but ultimately remains agnostic whether self and agency are extended. Clark writes: "I am content to let the notions of self and agency fall where they will” (1997, p. 218). However, in his co-authored article with David Chalmers, The Extended Mind, Clark argues that the extended mind does suggest an extended self.

"Does the extended mind imply an extended self? It seems so [...] The information in Otto's notebook, for example, is a central part of his identity as a cognitive agent [...] To consistently resist this conclusion, we would have to shrink the self into a mere bundle of occurrent states, severely threatening its deep psychological continuity. Far better to take the broader view, and see agents themselves as spread into the world" (Clark and Chalmers 1998, p. 18).

So, on Clark and Chalmers' view, self and agenthood are extended and spread into the world. Baker (2009) denies this claim. She seems sympathetic to the extended mind thesis, but denies it entails an extended person. On an extended mind view, persons are constantly shifting collections of biological and artifactual parts, implying there is no continuity of personhood over time. Baker finds this hard to accept, because on her view there are enduring persons. It is important to note that artifacts might actually provide some stability for the continuity of personhood over time. Information stored in artifacts is typically more durable and stable than information stored in biological memory (Donald 1991). External information such as pictures, journal entries, significant objects, or indeed lifelogs is often very durable, potentially existing in our lifeworld for decades. Our biological bodies and cognitive capacities change, sometimes quite dramatically, during our lifetime. But some of the artifacts we keep 
in our homes or stored in our computers are quite durable, providing long-lasting information we can lock onto at various stages in our life (Clowes 2012).

A more specific example concerns Alzheimer's patients who structure their homes such that the location of objects such as clothing, food, cups, utensils, the telephone, the remote control, and so forth, is familiar to them. "Taking them out of their homes is literally separating them from large parts of their minds" (Dennett 1996, p. 138). Their self-structured environment, rather than being a constantly shifting collection of objects, is - in fact-quite stable, providing continuity for their memory and perhaps also for their self. A final example where external artifacts can provide stability for memory and self is Leonard Shelby, the protagonist from Christopher Nolan's film Memento. Due to an "accident", Leonard has a severe form of amnesia: the memories of his past before the accident are uneffected, but he is now only able to remember the last seven minutes of his conscious life. So every seven minutes, he reawakens as if he sees the world for the first time. To deal with his memory loss, he develops strategies to communicate to his future self (Schechtman 2008). He makes polaroid photos which he annotates and labels with information; particularly crucial information is tattooed on his body. Leonard's tattoos have both semantic and episodic components (Sutton 2009) and function to partly replace his biological memory systems, in that way providing some stability for memory and self.

Olsen (2011) argues that if Otto's notebook is part of Otto as a person, it means that persons are not purely biological organisms but organisms-plus-external-parts. This implies that Otto is not his body, a conclusion difficult to accept for Olson who defends a view on personal identity, arguing that we basically are human animals. On Olsen's view, we are our biological bodies and our mental life and memories are not terribly important for our personal identity. Ultimately, Olson's denial of the extended self thesis is based on the denial of psychological properties (whether internally or partly externally instantiated) as a criterion for personal identity. I neither have the space nor the intention to try to solve the debate between psychological and biological approaches to personal identity. In this paper, I am assuming that psychological or cognitive properties are essential for both synchronic and diachronic aspects of personhood. The majority of philosophers working on personal identity agree with this, but some philosophers, such as animalists, would not agree with this claim.

Like Baker, Buller (2013) accepts the extended mind thesis, but denies it entails an extended person. A person, on his view, is an embodied agent with, in some cases, an extended mind. "Otto qua person coincides with the skin-and-skull boundary even though his mind is extended beyond this boundary" (2013, p. 600). Buller takes conscious experience as an essential element of personhood and because experience cannot be extended but only realized by an embodied brain, personhood cannot be extended either. I agree with Buller that consciousness or conscious experience is not extended, but I am not sure whether that means personhood is not extended either. Buller seems to imply that only conscious states are relevant for the self. But it is odd to say that, for instance, non-occurrent beliefs or non-occurrent information in memory are irrelevant for the self. Reducing the self to conscious states would, as Clark and Chalmers put it, 
"shrink the self to a bundle of occurrent states" (1998, p. 18). This seems too narrow a view to $\mathrm{me}^{4}$.

The above criticism, in one way or another, emphasize the unity of the biological organism as essential for personhood. But does personhood necessarily coincide with one's biological organism? In the next section, I suggest that the answer this question is "no". But before doing that, let me briefly point out that certain prostheses can communicate with the central nervous system and are physically connected to the body. These prostheses are under full control of their users and after a long and sometimes difficult period of training experienced as a transparent part of their embodied self (Clark 2007). Likewise, a blind man's cane is not so much part of his external environment, but absorbed by his body schema, transparent in use, and therefore part of the apparatus with which he encounters the world. It seems that personhood might not always coincide with the biological body. If prostheses and other tools can be experienced as transparent parts of the embodied self, then why not a notebook or other cognitive artifact?

\section{Distributed selves}

Two questions are often distinguished in relation to personal identity. First, what defines being a person? Second, is personhood persistent over time? The first question is concerned with synchronic aspects and the second with diachronic aspects of personal identity. Extended and distributed cognition have important implications for both of these questions.

\subsection{External resources and the synchronic self}

Rather than stipulating the metaphysical essence of personhood in terms of necessary and sufficient conditions, I use the concept of practical identity (Mackenzie 2008; Mackenzie and Walker 2015). Notions of practical identity try to answer questions about who we are as persons and what characterizes our first-personal perspective. An important element of our practical identity are our cognitive capacities, i.e., what we are cognitively capable of. ${ }^{5}$ If our cognitive capacities are important for our personhood and if cognitive artifacts are "the things that make us smart" (Norman 1993), then such artifacts are important for a synchronic conception of personhood. This is supported by the fact that humans often define themselves partly in terms of the cognitive skills they have. We see ourselves as analytical thinkers, as creative, as good problem-solvers, as good at language, and so forth. This is sometimes reflected in the jobs we have. We become engineers because we are good at analytical thought, we become designers

\footnotetext{
4 A reviewer pointed out that Locke's original memory criterion focused on consciousness too. In fact, memory was Locke's way of explaining the notion of temporally extended consciousness; memory makes the idea of a temporally extended consciousness fall within the experience-centered empiricist outlook. Many neo-Lockeans, including Schechtman, include non-occurrent states in their notion of psychological continuity.

5 There are, of course, other capacities that are important for our practical identity such as our capacity for consciousness and emotions.
} 
because we are creative, we become writers because we are good at language, etc. Having certain cognitive capacities is thus important for the kind of person we are. ${ }^{6}$

Extended and distributed cognition theory have extensively studied how we use artifacts to aid our cognition and problem-solving abilities (Norman 1993; Hutchins 1995; Kirsh 1995; Hollan et al. 2000). We have seen that embodied agents like us have limited information-storage and processing capacities. To complement these limitations, we use maps, diagrams, models, diaries, timetables, textbooks, calculators, computer systems, and many other artifacts to help us perform our cognitive tasks such as planning, navigating, calculating, learning, and remembering. We also rely on and interact with other people to complete our cognitive tasks (Wegner 1995; Sutton et al. 2010; Harris et al. 2010). Our cognitive capacities are thus relational in that they often depend on social and artifactual structures in the environment in which we are situated. Ontogenetically, our cognitive capacities develop by interacting with parents, caregivers and teachers as well as artifacts like abacuses, multiplication tables, textbooks, learning applications in computer systems, and so on. Other people like teachers, parents, or peers often teach us how to successfully use such artifacts to achieve our cognitive goals. Our embodied brains learn to incorporate people and artifacts into our problem-solving routines, in that way transforming and augmenting the way we think and remember. If we remove the external resource from the integrated system, our cognitive competences will drop. Without incorporating other people and artifacts into our cognitive practices, we simply would not have the same cognitive capacities. For this reason, external resources are essential for our cognitive capacities in the here-and-now and thus also for our synchronic personhood.

\subsection{External resources and the diachronic self}

Psychological continuity theories of personal identity often focus on memory as the criterion for persistence of personhood over time. Such views, dating back to John Locke, argue that someone in the present is the same person as someone in the past when that former person remembers having the experiences of the later person. For personhood to persist over time, there must thus be direct memory connections to past experiences. So the content of a memory at $t_{2}$ provides a cognitive connection to an experience had at $\mathrm{t}_{1}$, in that way creating a link between two time-slices of a person. On such a neo-Lockean view, our memory system is seen as a storehouse in which individual memories are stored for later retrieval in their original form and content.

However, Schechtman (1994) argues that human biological memory often does not provide such direct memory connections between two discrete states of consciousness. Rather, we summarize and condense important life experiences into a narrative. This is not to say that we do not have direct and specific memories of past experiences, we do. Schechtman's point, I take it, is that most of our autobiographical memories are also integrated into a larger narrative structure. We often remember that we did something, but rarely remember specific details of an event. For example, we may remember

\footnotetext{
6 If, for example, someone has a stroke or other kind of brain injury and loses part of one's memory or language capacity, that would surely be a change to the person.
} 
that we went to see the film Interstellar last year, but have trouble remembering specific images or details of its plot. Whilst we may remember a few specific details, we certainly do not remember the entire film. Memories are rarely exact, detailed replicas of an event or experience but are often condensed into general summarised structures, containing only the gist of things and are in some cases even inaccurate. Thus, focussing on direct memory connections to past experiences is insufficient for establishing psychological continuity of personal identity.

Schechtman (1996) has therefore developed a notion of personal identity that seeks to explain the diachronic constitution of our self in terms of a narrative. She argues that "We constitute ourselves as persons by coming to understand our lives as narratives with the form of the story of a person's life" (2012, p. 335). Summarising and condensing autobiographical memories makes sense as a cognitive strategy because we receive an overwhelming amount of information about our own lives. "In autobiographical memory the information about our lives that is constantly coming in should be reconstructed as a more concise and comprehensible narrative which emphasises the most significant factors of past experiences and depicts general and longstanding patterns or activities with representative examples" (1994, p. 11).

To better understand the relation between autobiographical memory and one's narrative, Schechtman presents an analogy between an archive and a biography. An archive contains all the historical facts of a person, whereas a biography is an integrated and coherent story of someone's life. To get a sense of the person behind the historical facts we need a biographer to make sense of the events, looking for patterns, anomalies, significant and insignificant events, and causal connections between events. Only when the facts are interpreted and integrated into a narrative, does a real person emerge. There is, however, an important difference: we constantly construct and revise our biography throughout our lives. Because our life is continuously unfolding, our narrative keeps changing. Over time, we have new significant experiences (e.g., graduating, marriage, divorce, new job, moving, traveling, death of a loved one, new friendships, and so on), which are then integrated into the overall narrative. Our narrative is thus a dynamic structure and the relationship we have to our narrative might change. Events that used to be important to us may now appear to be less important, and vice versa. Another difference is that most people do not have a biographer that interprets the facts and constructs a narrative, but make their own autobiographical narratives.

How do cognitive artifacts relate to our autobiographical narrative? I now argue that external artifacts can, in some cases, play an essential and constitutive role in one's autobiographical narrative and thus also in one's personal identity. This is particularly the case for people with memory disorders such as traumatic brain injury, mild cognitive impairment, Alzheimer's disease or other forms of dementia. Such patients suffer from a decline in their memory capacities, including their autobiographical memory. Psychological research has shown that this has a negative impact on their sense of self (Addis and Tippett 2004). On Schechtman's narrative self-constitution view, "the limits of a person are determined by the limits of a narrative, and the integrity of a single person consists in the unity of a narrative" (2012, p. 336). If memory disorders disintegrate one's autobiographical narrative, then they also disintegrate one's personal identity. 
In a somewhat similar way as Otto extends his semantic memory when using his notebook, artifacts may extend one's autobiographical memory. Specifically, cognitive artifacts can help to maintain the integrity, delay the disintegration, or in some cases replace one's autobiographical narrative. Lifelogging technologies, in particular, are useful to achieve these goals (Berry et al. 2007; Doherty 2012; Crete-Nishihata 2012). A striking example in this context is SenseCam, creating a visual narrative of one's daily life by taking a picture with a certain interval or when its sensors detect a change in environmental conditions. Berry et al. (2007) performed one of the first empirical studies of a patient with amnesia, using SenseCam to develop a photographic diary as to improve autobiographical memory. They showed that reviewing SenseCam images of personal experiences improves consolidation and retrieval of autobiographical memories for specific events, both on a short and long term. In similar research, Loveday and Conway (2011) demonstrate that SenseCam images are more effective than written records of personal experiences in cueing what they refer to as otherwise "inaccessible memories". So the images are necessary to evoke memories, otherwise they are likely to remain inaccessible. SenseCam images have this causal efficacy because they are cognitively comparable with biological memory in that "they are visual, represent short time slices of experience, they are time compressed and fragmentary, they are formed outside intentional awareness, they preserve the perspective of the individual at the time of the event, and they are temporarily ordered" (Loveday and Conway 2011, pp. 701-702). There are thus a lot of similarities between biological autobiographical memory and SenseCam images.

More recently, Crete-Nishihata (2012) used SenseCams and other lifelogging technologies to create a digital narrative of people with memory disorders. Their project aims to understand the implications of personal memory technologies for cognitively impaired persons. They report on three of their projects. In the first, they created a "multimedia biography" for twelve people with mild cognitive impairment or Alzheimer's disease. These multimedia biographies consist of photos, home movies, documents, letters, music, and narration complied into a digital video that represents a person's life history. The patients and their family members provided the material and also directed the script and storyboard of the narrative. These biographies are between 15 and $60 \mathrm{~min}$ and are divided into a series of acts, each with a number of scenes. The acts are often major life events or stages such as adolescence, marriage, career, and hobbies, which are told chronologically. The researchers write that "family members and participants perceived the multimedia biographies as a means for preserving the personhood of their loved one..." (2012, p. 101, italics added).

Personalised photos and music selections often elicited the strongest emotional responses. The researchers learned that telling a life story is essentially a reconstructive process. It is not so much "about documenting clear objective series of facts. Instead, each user of personal memory technologies may perceive the past in different ways and want their interpretation reflected in the media" (2012, p. 103). This shows that one's autobiographical narrative is socially constructed. An important conclusion is that "intimate technologies for constructing personal identity and experiences must allow editing of the "past" to match one's current viewpoint" (2012, p. 103). This is consistent with Schechtman's narrative view, as she pointed out that the relation we have to our narrative changes: events that used to be important can now be less 
important to us. So being able to change or edit one's lifelog such that it is consistent with one's narrative is an important property of lifelogs and multimedia biographies.

In their second and less extensive study, they made a multimedia biography that also included recently taken SenseCam images for a patient with mild Alzheimer's disease. In this study, the aim was to examine the social-psychological effects of multimedia biographies by studying in more detail the authoring and viewing processes, both of which had a positive impact on the patient's apathy and self-image. So, not just autobiographical memory, but also one's self-image improves when using lifelogging technology.

In their third study, they compared two ways of viewing SenseCam images. An unedited version containing all images and an edited version containing only 24 images and narrated by the partner of the cognitively impaired person. The results were mixed as three out of five patients preferred the unedited version as there is more information and detail to prompt their memories. Noteworthy is that the partners were the editors and narrators, the patients themselves were not involved. One of the patients pointed out that the edited version made her feel a little annoyed because her partner picked things that meant something to him, but not things that meant something to her. So, again, authorship of and agency over the content of the lifelog is thus (perhaps obviously) an important factor for its cognitive and narrative efficacy.

Are multimedia biographies and lifelogs mere cues to activate or trigger internally encoded memories or can they perhaps be seen as genuine external memories? The research above seems to suggest they are cues to internal memory. However, if someone is unable to activate or retrieve an autobiographical memory and can only retrieve it by using an external cue, then it seems plausible to say that the external cue is part of the overall memory system. The processing of memories is often divided in three stages: encoding, storing, and retrieving. Memory disorders may occur at any of these stages. An autobiographical memory may still be stored in the brain, but an agent may not be able to retrieve it without help (Loveday and Conway 2011). If someone needs an external cue to successfully retrieve a memory, then we might say the cue is part of the overall distributed memory system. Crete-Nishihata (2012) looked at patients with mild cognitive impairment or in the first stages of Alzheimer's disease. These patients still have a reasonably intact memory system. However, in some cases, patients will have (much) lesser intact memory systems and have trouble encoding, storing and retrieving memories. For those patients, a lifelog can literally be their autobiographical memory in the same way as Otto's notebook is literally his semantic memory.

\section{Enhancement or diminishment?}

In the previous subsection, I mainly focussed on people with memory impairments and how they use lifelogging technologies such as SenseCams to aid or supplement their autobiographical memory. It is difficult to see these assistive technologies as cognitively, morally, or culturally undesirable as they help people to deal with their cognitive impairments, thereby increasing their autonomy, which results in a more positive self-image and a better quality of life. However, lifelogging technologies are 
also used by cognitively unimpaired agents (O'Hara et al. 2008). Some lifeloggers, such as Gordon Bell, take it quite seriously and have extensive lifelogs of personal experiences and other personally-relevant information, going back decades. Bell and most other members of the quantified self movement have an intact autobiographical memory system and therefore a different relation to their lifelog. For some of the above discussed patients, their lifelog or multimedia biography is (at least potentially) constitutive of their autobiographical narrative. Whether lifelogs are constitutive of other agents' autobiographical memory, depends on the way they are used and how deeply they are integrated into one's cognitive system. The degree of integration of a lifelog into autobiographical memory depends on factors such as the availability of the lifelog, how often it is used, its transparency in use, the ease with which it can be edited, and its capacity to capture relevant experiences that are consistent with or fit into one's narrative. Also, it is likely that lifelogs contain images of experiences that its user has (long) forgotten. If the SenseCam had not captured the experience, its user might have never thought about it again, implying that the lifelog could be a necessary cue for internally encoded memories.

Regardless of whether lifelogs are constitutive of autobiographical memory, it is likely that they transform onboard autobiographical memory systems. An effect of lifelogging could be that lifelogs reduce the detail and amount of internally encoded autobiographical memories. If users know their SenseCam reliably records images of personal experiences and regularly review their lifelog, they might put less effort (consciously or unconsciously) into encoding the experience in biological memory. Empirical research in cognitive psychology shows that when we know information is available in some external media, we tend to put less effort into memorizing that information internally (Sparrow et al. 2011). Similarly, people taking pictures of objects in an art museum, have less memories of the photographed objects as compared to museum objects they had not photographed (Henkel 2014). When writing about lifelogging technology, Sherry Turkle asks: "If technology remembers for us, will we remember less?" (2011, p. 300). Research thus suggests the answer to this question might be "yes". Given the human cognitive system is a pragmatic system evolved to make the best of its informational environment, this should not come as a surprise. In our recent cognitive evolution, we have consistently relied on external information to perform our cognitive tasks (Donald 1991). Modern lifelogging technology is just the latest in a long history of memory technologies.

Furthermore, narrative identity is as much about forgetting as it is about remembering. For whatever reason, we sometimes want to forget an experience, but lifelogging may not always allow one to do that, given its focus on "total recall" (MayerSchonberger 2011; Jacquemard et al. 2014). Commenting on this issue, Luciano Floridi points out: "The more memories we accumulate and externalise, the more narrative constraints we provide for the construction and development of personal identities. Increasing our memories means decreasing the degree of freedom we might enjoy in defining ourselves" (2011, p. 562). It seems true that a lifelog not only helps one to remember experiences — which is often beneficial, depending on one's situation-but also limits the options one has to construct one's narrative. Awkward discrepancies may potentially emerge between one's lifelog and internally constructed narrative. However, having control over the contents of one's lifelog and being able to edit it, 
seems to, at least potentially, solve this issue. ${ }^{7}$ It is also important to note that similar uncomfortable moments may occur when reading one's past journal entries or seeing photos of past events that remind one of experiences one rather forgets. Moreover, sometimes awkward experiences may actually be meaningful for one's autobiographical narrative. In the film, Eternal Sunshine of the Spotless Mind, the protagonist removes the memories of his failed romantic relationship, thereby removing it from his overall narrative. The point of the film, however, is that such experiences are part of a meaningful and authentic life.

One might ask what would happen if photos of events that one did not actually experience are somehow included in someone's lifelog or multimedia biography. ${ }^{8}$ The person in question, further, does not realise those photos are not taken by his or her own SenseCam and believes them to be true and part of the narrative. This means that one's digital narrative can be inconsistent with (at best) or potentially even distort reality (at worst). ${ }^{9}$ However, internally stored narratives are not without inconsistencies and inaccuracies either. Schechtman outlined two narrative constraints: the reality and the articulation constraint. The reality constraint says that the narrative must be consistent with the laws of nature. So the protagonist cannot live as long as Methuselah, travel faster than the speed of light, or be at two places at the same time. The articulation constraint says that the person must be able to articulate parts of the narrative when appropriate. But note that Schechtman does not claim that the narrative must be consistent with actual events. So false or inaccurate memories may (and often are) be part of one's narrative, either internally or externally stored. People sometimes leave out events or exaggerate others. One's narrative rarely is a complete and accurate reflection of one's life.

Finally, a number of situated cognition theorists argue that the human self is essentially a soft self. On Clark's extended cognition view, for example, "our best tools and technologies literally become us: the human self emerges as a soft self, a constantly negotiable collection of resources easily able to straddle and criss-cross the boundaries between biology and artifact" (Clark 2007, p. 278). If cognition and self are indeed distributed, the constitutive parts of those distributed systems obtain a particular moral status. Destroying Otto's notebook, for example, "has an especially worrying moral aspect: it surely is harm to the person, in about as literal a sense as can be imagined" (Clark 1997, p. 215). Neuroethics and the cognitive enhancement debate have

\footnotetext{
7 A reviewer pointed out that emphasizing control over the contents of one's lifelog can be interpreted as claiming that the locus of personhood is still brain-based. My view is that agency and the locus of personhood can be distributed across humans and cognitive artifacts such as SenseCam-generated lifelogs. I think agency is distributed because the SenseCam automatically takes pictures whose content we typically cannot change, but the human agent often has to edit the lifelog. So both components in the larger systems have some form of agency and the equilibrium may shift between the artifactual and biological components, depending on each specific case. Furthermore, in the typical extended mind cases (Clark and Chalmers 1998), agency is largely located in the biological organism. However, in larger distributed cognitive systems, for example Hutchins' (1995) example of ship navigation, humans may not necessarily be the center and controller of distributed systems. For more discussion on this topic see Hutchins (2014).

8 This is related to the problem of q-memory as outlined in Parfit (1984).

9 These are important epistemological issues to further explore. They also tie in with the extended knowledge debate (e.g., Michaelian 2014), which has to do in part with the possibility of assigning credit to agents who rely on external cognitive resources for their epistemic accomplishments, including those are false.
} 
traditionally focussed on technologies that interact with or alter the brain such as transcranial magnetic stimulation, psychopharmaceuticals, brain-computer interfaces, and so on. However, the argument developed in this paper implies that cognitive artifacts should get a much more prominent role in neuroethics (Levy 2007a,b). Thus, if the mind and self are, in some cases, partly constituted by external information, we ought to treat that information in a similar way as we treat mental states instantiated purely by the brain. What does this mean concretely? In addition to traditional legal and moral issues of artifact-ownership, it means we should not interfere with people's distributed minds and selves (Heersmink 2015). So we should not interfere with people's lifelogs, diaries, journals, photo albums and other artifacts related to autobiographical memory. On this view, we also should not take Alzheimer's patients out of (or change) their personalized, self-structured environments, as that would reduce their minds and selves and worsens their situation.

\section{Conclusion}

In this paper, I argued that not just memory and cognition, but also personal identity depends on and is sometimes constituted by the social and technological environment in which we are situated. The complex web of relations we develop and maintain with other people and artifacts partly constitutes our self, implying that we are essentially a soft self. Personal identity can thus neither be reduced to psychological structures instantiated by the brain nor by biological structures instantiated by our biological organism. If our minds and selves are indeed changing combinations of biological and artifactual resources, we should be careful in selecting and creating the most appropriate resources available, as these artifacts partly determine who we are. For this reason, neuroethics should focus more on artifacts and material culture and develop approaches to determine the best ways to distribute our selves. The view developed in this article has conceptual, methodological, and normative implications: we should broaden our concepts of the self as to include social and artifactual structures, focus on external memory systems in the (empirical) study of personal identity, and not interfere with people's distributed minds and selves.

Acknowledgements I would like to thank Neil Levy for helpful advice, Paul Smart and Robert Clowes for discussion on embodiment and the self, and two anonymous reviewers for their helpful comments and suggestions.

\section{References}

Addis, D. R., \& Tippett, L. J. (2004). Memory of myself: Autobiographical memory and identity in Alzheimer's disease. Memory, 12(1), 56-74.

Anderson, J. (2008). Neuro-prosthetics, the extended mind, and respect for persons with disability. In M. Düwell, C. Rehmann-Sutter, \& D. Mieth (Eds.), The contingent nature of life: Bioethics and limits of human existence (pp. 259-274). Heidelberg: Springer.

Baker, L. R. (2009). Persons and the extended mind thesis. Zygon, 44(3), 642-658.

Beach, K. (1988). The role of external mnemonic symbols in acquiring an occupation. In M. M. Gruneberg, P. E. Morris, \& R. N. Sykes (Eds.), Practical aspects of memory (pp. 342-346). Chichester: Wiley. 
Bell, G. M., \& Gemmell, J. (2009). Total recall: How the e-memory revolution will change everything. New York: Dutton.

Berry, E., et al. (2007). he use of a wearable camera, SenseCam, as a pictorial diary to improve autobiographical memory in a patient with limbic encephalitis: A preliminary report. Neuropsychological Rehabilitation, 17(4-5), 582-601.

Buller, T. (2013). Neurotechnology, invasiveness and the extended mind. Neuroethics, 6(3), 593-605.

Bush, V. (1945). As we may think. The Atlantic, 176(1), 101-108.

Clark, A. (1997). Being there: Putting brain, body, and world together again. Cambridge, MA: MIT Press.

Clark, A. (2005). Intrinsic content, active memory and the extended mind. Analysis, 65(285), 1-11.

Clark, A. (2007). Re-inventing ourselves: The plasticity of embodiment, sensing, and mind. Journal of Philosophy and Medicine, 32(3), 263-282.

Clark, A., \& Chalmers, D. (1998). The extended mind. Analysis, 58(1), 7-19.

Clowes, R. W. (2012). Hybrid memory, cognitive technology and self. In Y.J. Erden \& J.M. Bishop (Eds.), Proceedings of AISB/IACAP world Congress (pp. 4-13).

Crete-Nishihata, M., et al. (2012). Reconstructing the past: Personal memory technologies are not just personal and not just for memory. Human-Computer Interaction, 27(1-2), 92-123.

Dennett, D. (1996). Kinds of minds: Towards an understanding of consciousness. New York: Basic Books.

Doherty, A. R., et al. (2012). Experiences of aiding autobiographical memory using the SenseCam. HumanComputer Interaction, 27(1-2), 151-174.

Donald, M. (1991). Origins of the modern mind: Three stages in the evolution of our cognitive system. Cambridge, MA: Harvard University Press.

Floridi, L. (2011). The informational nature of personal identity. Minds and Machines, 21, 549-566.

Harris, C. .B, Keil, P. G., Sutton, J. \& Barnier, A. J. (2010). Collaborative remembering: When can remembering with others be beneficial? In W. Christensen, E. Schier \& J. Sutton (Eds.), Proceedings of the 9th conference of the Australasian Society for Cognitive Science (pp. 131-134).

Henkel, L. A. (2014). Point-and-shoot memories: The influence of taking photos on memory for a museum tour. Psychological Science, 25(2), 396-402.

Heersmink, R. (2015). Extended mind and cognitive enhancement: Moral aspects of cognitive artifacts. Phenomenology and the Cognitive Sciences. doi:10.1007/s11097-015-9448-5.

Hodges, S., Berry, E., \& Wood, K. (2011). SenseCam: A wearable camera that stimulates and rehabilitates autobiographical memory. Memory, 19(7), 685-696.

Hollan, J., Hutchins, E., \& Kirsh, D. (2000). Distributed cognition: Toward a new foundation for humancomputer interaction research. Transactions on Computer-Human Interaction, 7(2), 174-196.

Hutchins, E. (1995). Cognition in the wild. Cambridge, MA: MIT Press.

Hutchins, E. (2014). The cultural ecosystem of human cognition. Philosophical Psychology, 27(1), 34-49.

Jacquemard, T., Novitzky, P., O’Brolchain, F., Smeaton, A. F., \& Gordijn, B. (2014). Challenges and opportunities of lifelog technologies: A literature review and critical analysis. Science and Engineering Ethics, 20(2), 379-409.

Kirsh, D. (1995). The intelligent use of space. Artificial Intelligence, 73(1-2), 1-52.

Levy, N. (2007a). Rethinking neuroethics in the light of the extended mind thesis. American Journal of Bioethics, 7(9), 3-11.

Levy, N. (2007b). Neuroethics: Challenges for the 21st century. Cambridge: Cambridge University Press.

Loveday, C., \& Conway, M. (2011). Using SenseCam with an amnesic patient: Accessing inaccessible everyday memories. Memory, 19(7), 697-704.

Mackenzie, C. (2008). Introduction: Practical identity and narrative agency. In C. Mackenzie \& K. Atkins (Eds.), Practical identity and narrative agency (pp. 1-28). New York: Routledge.

Mackenzie, C., \& Walker, M. (2015). Neurotechnologies, personal identity, and the ethics of authenticity. In J. Clausen \& N. Levy (Eds.), Handbook of neuroethics (pp. 373-392). Dordrecht: Springer.

Mayer-Schonberger, V. (2011). Delete: The virtue of forgetting in the digital age. Princeton, NJ: Princeton University Press.

Menary, R. (2007). Cognitive integration: Mind and cognition unbound. London: Palgrave McMillan.

Michaelian, K. (2014). JFGI: From distributed cognition to distributed reliabilism. Philosophical Issues, 24(1), 314-346.

Michaelian, K., \& Sutton, J. (2013). Distributed cognition and memory research: History and current directions. Review of Philosophy and Psychology, 4(1), 1-24.

Norman, D. (1993). Things that make us smart: Defending human attributes in the age of the machine. New York: Basic Books. 
O'Hara, K., Tufflied, M. M., \& Shadbolt, N. (2008). Lifelogging: Privacy and empowerment with memories for life. Identity in the Information Society, 1(1), 155-172.

Olsen, E. T. (2011). The extended self. Minds and Machines, 21(4), 481-495.

Parfit, D. (1984). Reasons and persons. Oxford: Oxford University Press.

Rowlands, M. (1999). The body in mind: Understanding cognitive processes. Cambridge: Cambridge University Press.

Schechtman, M. (1994). The truth about memory. Philosophical Psychology, 7(1), 3-18.

Schechtman, M. (1996). The constitution of selves. Ithaca, NY: Cornell University Press.

Schechtman, M. (2008). Diversity in unity: Practical unity and personal boundaries. Synthese, 162(3), $405-423$.

Schechtman, M. (2012). The story of my (second) life: Virtual worlds and narrative identity. Philosophy and Technology, 25(3), 329-343.

Smart, P., Heersmink, R., \& Clowes, R. (2016). The cognitive ecology of the internet. In S. Cowley \& F. Vallée-Tourangeau (Eds.), Cognition beyond the brain: Computation, interactivity and human artifice (2nd ed.). Dordrecht: Springer.

Sparrow, B., Liu, J., \& Wegner, D. M. (2011). Google effects on memory: Cognitive consequences of having information at our fingertips. Science, 333(6043), 776-778.

Sutton, J. (2009). The feel of the world: Exograms, habits, and the confusion of types of memory. In A. Kania (Ed.), Philosophers on Memento (pp. 65-86). London: Routledge.

Sutton, J. (2010). Exograms and interdisciplinarity: History, the extended mind, and the civilizing process. In R. Menary (Ed.), The extended mind (pp. 189-225). Cambridge, MA: MIT Press.

Sutton, J., Harris, C. B., Keil, P., \& Barnier, A. J. (2010). The psychology of memory, extended cognition, and socially distributed remembering. Phenomenology and the Cognitive Sciences, 9(4), 521-560.

Theiner, G. (2013). Transactive memory systems: A mechanistic analysis of emergent group memory. Review of Philosophy and Psychology, 4(1), 65-89.

Turkle, S. (2011). Alone together: Why we expect more from technology and less from each other. New York: Basic Books.

van den Hoven, E. (2014). A future-proof past: Designing for remembering experiences. Memory Studies, $7(3), 373-387$.

van den Hoven, E., Cas, C., \& Whittaker, S. (2012). Introduction to this special issue on designing for personal memories: Past, present, and future. Human-Computer Interaction, 27(1-2), 1-12.

Wegner, D. M. (1995). A computer network model of human transactive memory. Social Cognition, 13(3), 319-339.

Wegner, D. M., Giuliano, T., \& Hertel, P. T. (1985). Cognitive interdependence in close relationships. In W. J. Ickes (Ed.), Compatible and incompatible relationships (pp. 253-276). New York: Springer-Verlag.

Wilson, R., \& Lenart, B. (2014). Extended mind and identity. In J. Clausen \& N. Levy (Eds.), Handbook of neuroethics (pp. 423-439). Dordrecht: Springer. 